\title{
Ranking zones model - a multicriterial approach to the spatial management of urban areas
}

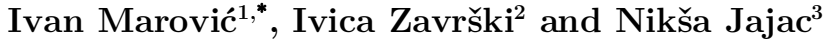 \\ ${ }^{1}$ Faculty of Civil Engineering, University of Rijeka \\ Radmile Matejčić 3, 51000 Rijeka, Croatia \\ E-mail: 〈ivan.marovic@uniri.hr〉 \\ ${ }^{2}$ Faculty of Civil Engineering, University of Zagreb \\ Fra Andrije Kačića-Miošića 26, 10000 Zagreb, Croatia \\ E-mail: 〈zavrski@grad.hr〉 \\ ${ }^{3}$ Faculty of Civil Engineering, Architecture and Geodesy, University of Split \\ Matice hrvatske 15, 21000 Split, Croatia \\ E-mail: 〈njajac@gradst.hr〉
}

\begin{abstract}
Urban investment planning is highly complex and different views are provided by stakeholders and experts as to the scope, scale and potential solutions. The evaluation of such investments requires explicit consideration of multiple, conflicting and incommensurate criteria that have an important social, economic, and environmental influence on various stakeholders in different ways. To take into account all the dimensions, the proposed model is the Ranking Zones Model (RZM), based on PROMETHEE methods. The RZM comprises several steps providing a rank-list of all observed zones. It helps decision-makers come up with consistent decisions as to which zones to invest in and, at the same time, provides reassurance that the decision was based on a proper comparison of all relevant urban zone areas. The advantage of this approach is that even with a change in the decision-making structure, the actual procedure remains consistent.
\end{abstract}

Key words: multicriteria, decision support, spatial management, prioritization, urban development

Received: October 4, 2014; accepted: December 13, 2014; available online: March 30, 2014

DOI: $10.17535 /$ crorr. 2015.0008

\section{Introduction}

Urbanization is defined by the United Nations as the movement of people from rural to urban areas [16], resulting in urban populations constantly increasing

* Corresponding author. 
compared to those in rural areas. By $2030,60 \%$ of the world's population will be living in urban areas, of which $84 \%$ refer to populations from developed countries [16]. Knowing this, urban decision-makers (both policy makers and

city planners) face difficulties in implementing sustainable management of urban areas.

Urban areas are constantly changing as they encroach into new territories or as existing areas are re-developed through private and public investments. Planning and analysis of these investments can are highly complex, with numerous different views among stakeholders and experts as to the scope, scale and potential solutions. Evaluating these investments requires consideration of multiple, conflicting and incommensurate criteria that can have an important social, economic, and environmental influence on various stakeholders differently. It involves evaluating options or alternatives that have qualitative and quantitative dimensions. The Ranking Zones Model (RZM), based on PROMETHEE methods, is the model proposed for taking into account these dimensions [1]. The RZM comprises several steps: identifying zones in observed urban area, creating a hierarchical structure of goals and criteria, criteria weighting, and ranking zones according to defined criteria. The outcome of the model is a rank-list of all observed zones that assists decision-makers in coming up with consistent decisions on which zones to invest in and, at the same time, provides a reassurance that the decision was based on a proper comparison of all relevant urban zone areas. The advantage of this approach to decision-making owes to the fact that even with changes to the structure of decision makers, the actual decision-making procedure remains consistent. The development of the presented model has been based on a real-world urbanism case study in the city of Split, Croatia.

\section{Research context and review of literature}

Multiple actors representing various urban organizations from a number of disciplines (urban planning, architecture, engineering, geography, economics, finance, politics, sociology, etc.), have to work together at each level of a city management hierarchy for proper sustainable management of urban areas. Chakrabarty [3] has presented a concept of integrated urban management based on management theory and a systems approach, arguing that many principles of traditional management (such as the principles of productivity, social responsiveness and flexibility) are equally applicable to urban management for overcoming limitations. He has emphasized education in urban management to facilitate application of principles and management techniques, and the need to resolve urban issues in a resource-efficient manner while meeting the requirements of multiple stakeholders. Certainly, an integrated management approach is rather difficult in practice but that should not be an excuse. 
Firstly, an assessment of the urban area should be performed to upgrade urban management and make it more sustainable. The role of indicators is to measure performance. Several indicator-based approaches in assessing urban sustainability have been developed. Ugwu et al. [15] have examined available techniques for evaluating different aspects of sustainability using indicators. Zhang et al. [18] have used methodological foundations of various assessment methods to propose a classification, dividing them into three groups: system engineering, monetary evaluation and biophysical. Furthermore, based on research, Shen et al. [14] has provided a four-dimensional comparative analysis in terms of environment, economics, society and governance.

A survey conducted by Hanak et al. [4] has provided valuable insight that not all sustainable indicators in urban areas are weighted equally, thus providing decision makers with important data on citizen preferences for modelling urban areas. Their preliminary identification of indicators from a residential environment assessment has shown a high correlation between different cities, while their previous research [11] showed that the difference between key and margin indicators was about 40\%. Such differences are considerable when translated into money terms. Decision-makers can make significant savings in public budgets, i.e. optimize urban planning budgets, when considering these indicators.

In complex environments, where the word 'sustainable' is a constant prefix, the use of management information systems and multicriterial analysis is essential. It is important to keep in mind that the terms "urban sustainability", "sustainable city" and "sustainable community" refer to a desirable state, while "sustainable urbanization" and "sustainable urban development" refer to the process that leads to a desirable state.

Various decision support systems (DSS) have been devised to improve urban areas and make them more sustainable, whether it includes urban road infrastructure $[5,8]$, or overall value management of an urban area [10]. The application of multicriterial methods to planning and management in civil engineering is carried out in private investments (such as the problem of selecting a construction site [6] or selecting the best investment project [7]) and in public investments (such as public infrastructure project management financed by EU funds [13] or evaluation of public administration projects [12]).

\section{A multicriterial approach for spatial management of urban areas}

The Multiple Criteria Decision Aid (MCDA) approach provides a large set of tools to help decision-makers solve problems by taking into account several, often contradictory, points of view, as was earlier stated. In general, MCDA methods are divided into three large families [17]: 
- The unique synthesis criterion (consisting of aggregating different points of view into a unique function requiring subsequent optimization),

- The outranking synthesis approach (using methods which aim first to build an outranking relation representing a decision-maker's strongly established preferences based on the information at hand),

- The interactive local judgment approach (proposing methods that alternate calculation steps and dialogue steps).

For the priority-ranking problem in this paper, PROMETHEE methods, comprising PROMETHEE I (partial ranking) and PROMETHEE II (complete ranking), were chosen from among many multicriterial methods based on the experience of the authors in the field. These methods were used for comparing and ranking various alternatives that were simultaneously evaluated based on many quantitative and qualitative criteria. They belong to the class of outranking methods that comprise the poor dominance relation and assume the decision-maker is familiar with utility functions. As each alternative faces the other, the positive (Phi+) and negative (Phi-) outranking flow is calculated [1]. The positive outranking flow expresses how an alternative outranks all others, while the negative outranking flow expresses how an alternative is outranked by all others. Given that PROMETHEE I is obtained from the positive and negative outranking flows, the PROMETHEE II comprises the net outranking flow (Phi) [1, 2]. Since the net flow provides a complete ranking, it can be compared with the utility function. Phi offers the advantage that it is built on clear and simple preference information (weights and preference functions) and it relies on comparative statements rather than absolute statements [2].

This paper aims to examine the tactical problems that decision-makers frequently encounter in the management of urban areas. The Ranking Zones Model (RZM) solves poorly structured and unstructured problems on a tactical level, and is one of the models used in decision supports system for real estate value management [10].

\subsection{Establishing the Ranking Zones Model}

The model consists of two stages (two process groups): the preparatory processes and the implementation processes.

The implementation of these processes involves determination and analysis of the coverage area (i.e. identification of city boundaries and associated city zones) which is then followed by comparing the areas based on established criteria using means of multiple criteria analysis, finally leading to the solution, i.e. the best observed zone is identified. Preparatory processes stemming from the proposed model were linked to the GIS-database of Split, the Split Cadaster Office, and other existing data structure sources. The RZM implementation processes begin with phase 1 , dealing with the definition of goals and criteria for 
zone comparison, and the establishment of the importance (weight) of each criteria. This phase represents the key aspect of the model, because by defining comparison criteria we can create a unique hierarchical goal structure to which observed zones in an urban area are consistently referred to, where coincidently, they are linked to the main goal, which is development strategy.

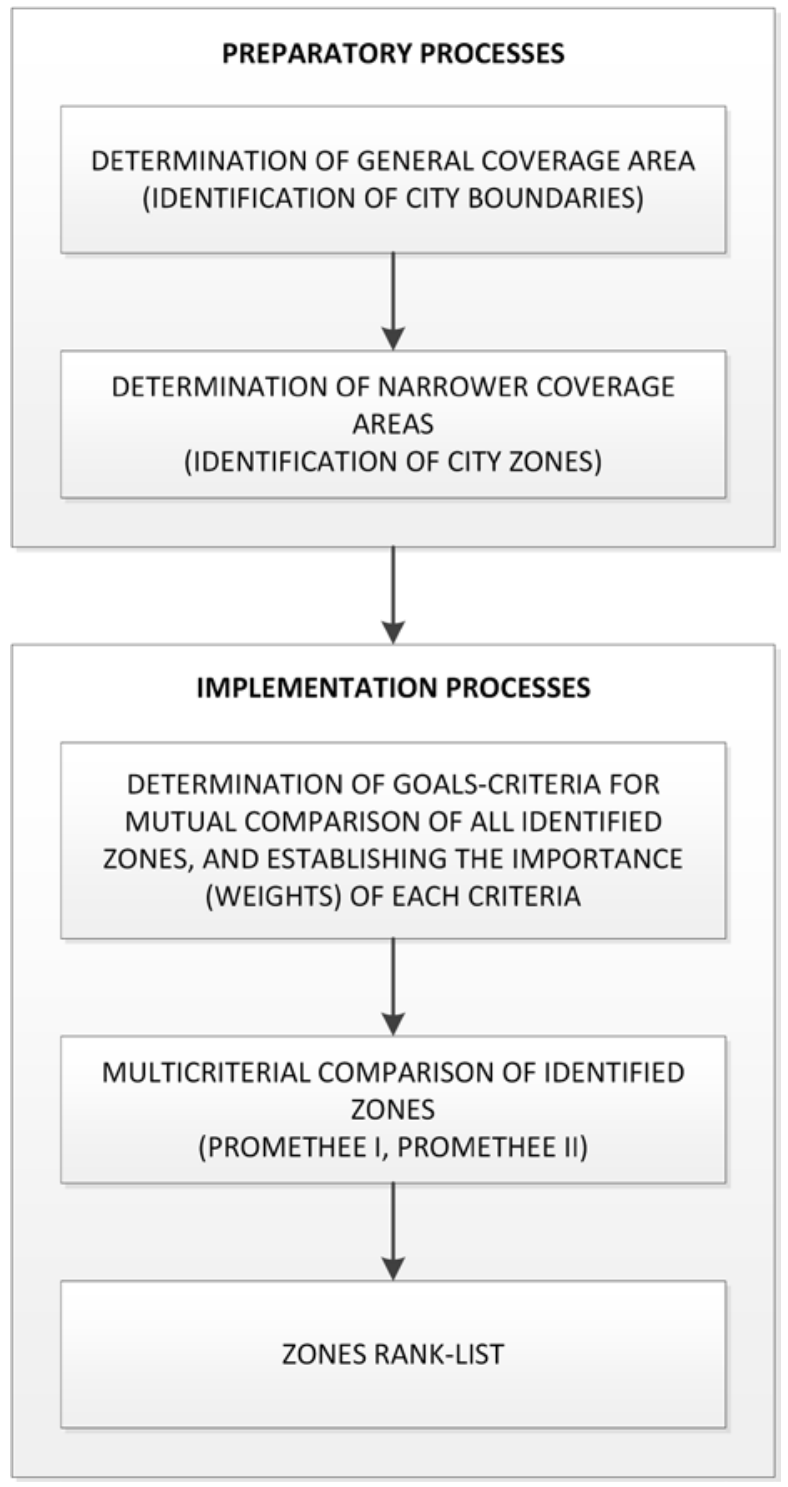

Figure 1: Ranking zones model (RZM)

In addition to defining criteria, "goal analysis" is useful in defining the goals that should be achieved by solving the defined problem [8, 12]. Setting 
goals is often tedious for decision makers because they might be convinced their goals are clear - even if they are not - and are frequently under pressure to make predetermined decisions. Generally, a structured approach is lacking which would otherwise provide a swift, efficient, and systematic analysis of the goals. In addition to the well-known methodology, experience and teamwork are the best guarantee of a successful goal analysis [10, 12].

Criteria are also a measure of system characteristics, which should be optimized to satisfy set goals. When using multicriterial analysis, criteria are usually sorted into the following classes [10]:

- Social-political criteria

- Ecological or safety criteria

- Economic criteria

- Technical and technological criteria.

Establishing a hierarchical goal structure begins by defining the main goal $(\mathrm{GC})$, followed by forming the group, i.e. forming the resource pool of experts (Figure 2). A selection of first-rank experts (E1R) generates the first-rank goals $(\mathrm{C} 1 \mathrm{R})$. Then, a selection of second-rank experts (E2R) generates the secondrank goals $(\mathrm{C} 2 \mathrm{R})$. This procedure generates the goals and establishes a goal hierarchy. Experts of any rank may be individuals, but they can also be groups of experts who may be tasked to determine one group of goals [10, 12] or all goals in one rank.

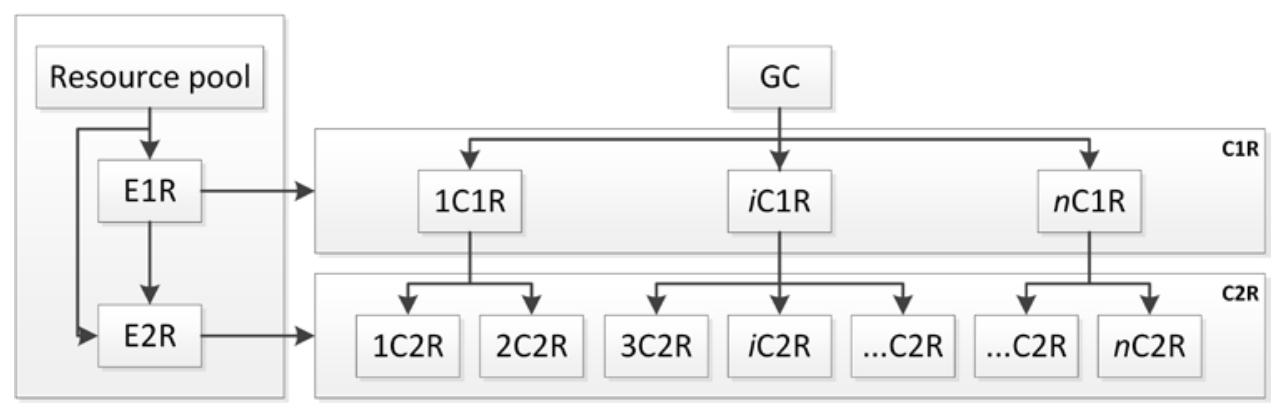

Figure 2: Hierarchical goal structure procedure

Decomposition of the main goal leads through the sub-goals to the criteria. When the goals on a particular decomposition level become clear (can be precisely described) and measurable (can be expressed quantitatively and qualitatively), they then become criteria $[5,10,12]$. After the entire hierarchical goal structure has been established, the importance is determined, i.e. a weight is assigned to each one, as not all criteria are equally important.

Determining the criteria weight, and subsequently the weight of sub-goals i.e. objectives, is the task of the experts, and depends on the level or rank where all the criteria are located and where weights are assigned to them by experts of 
that particular rank. That is performed using the same procedure as for establishing a hierarchical goal structure.

After the goals and criteria have been defined, and their weights determined accordingly, the next phase of implementation processes can be commenced, the process of ranking zones. Here, the PROMETHEE II method is used for obtaining a full ranking of options according to established criteria of comparison. Implementation of the method produces output information in the form of a rank-list of observed zones. This rank-list provides the decision maker with the basis for making a decision, especially when the rank-list is graphically presented.

\section{Results and discussion}

\subsection{Implementation of the Ranking Zones Model in the city of Split}

The described Ranking Zones Model (RZM) has been tested on the urban area of the City of Split, comprising 27 municipal areas. Data were collected from the beginning of 2011 till mid-2013. Although, there were some spatial changes in observed area during research period, this paper will only present results of the first modelling cycle (the first 12 months).

The RZM model has two parts (preparatory and implementation processes) and is used for solving poorly structured and unstructured problems on a tactical level. It answers the question, "Where to invest?" Once the city boundaries and zones within are identified and data collected (preparatory processes are finished), the implementation processes may commence.

The RZM implementation processes begin with phase 1, which is defining the goals and criteria for a comparison of observed zones, and establishing the importance (weight) of each criterion. This phase is the key aspect of the model, because by defining comparison criteria, a unique hierarchical goal structure is created with which consistent comparisons of zones can be made, that are at the same time tied to the main goal, the development strategy. Figure 3 illustrates the hierarchical goal structure for ranking zones in the City of Split (result of the procedure described in previous section), with the names of all identified goals, objectives and criteria shown in Table 1. 


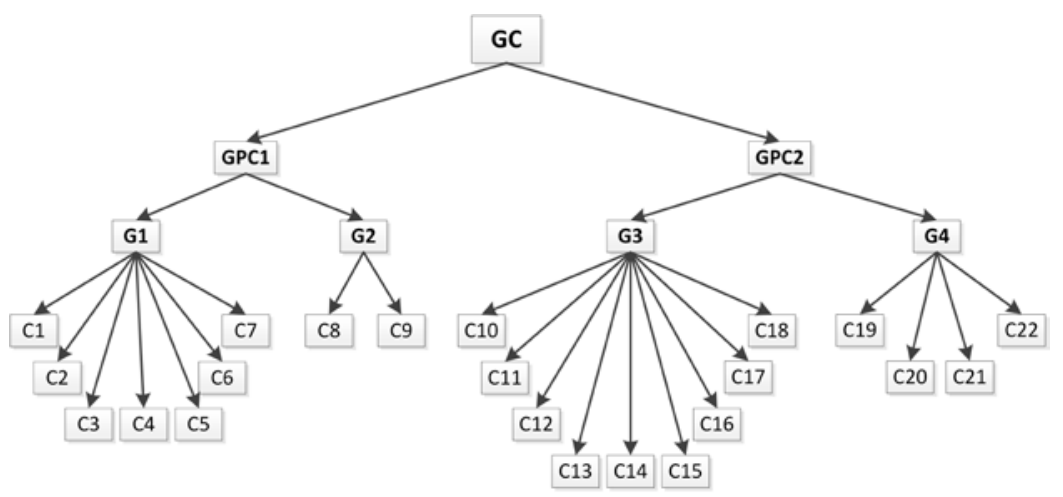

Figure 3: Hierarchical goal structure for ranking zones in the City of Split

The main goal (GC) and two main sub-goals (GPC1 and GPC2) are connected to the development strategy, while the procedure presented in Figure 2 was conducted for further decomposition. Finally, 22 criteria were identified which describe the social, ecological, technical, technological and economic aspects by which 27 identified zones will be compered by.

\begin{tabular}{|c|c|c|c|}
\hline Code & Goal, objectives and criteria & Weight & $\begin{array}{c}\text { Min/ } \\
\text { Max }\end{array}$ \\
\hline GC & Sustainable real estate value management of urban areas & 1.00 & MAX \\
\hline GPC1 & Improving the quality of life & 0.48 & MAX \\
\hline GPC2 & Technical-economic compatibility & 0.52 & MAX \\
\hline G1 & Social benefits & 0.27 & MAX \\
\hline G2 & Minimum environment endangerment & 0.21 & MAX \\
\hline G3 & Technical-urbanistic benefits & 0.20 & MAX \\
\hline G4 & Economic justification & 0.32 & MAX \\
\hline C1 & Population density & 0.03 & MAX \\
\hline C2 & Commercial property density & 0.03 & MAX \\
\hline C3 & Total property area & 0.01 & MAX \\
\hline C4 & Public building density & 0.04 & MAX \\
\hline C5 & Pedestrian paths intensity & 0.05 & MAX \\
\hline C6 & The intensity of cleaning public urban areas and municipal waste disposal & 0.05 & MAX \\
\hline C7 & Coverage and frequency of public transportation & 0.06 & MAX \\
\hline C8 & Ambient noise sensitivity & 0.10 & MIN \\
\hline C9 & Air pollution sensitivity & 0.11 & MIN \\
\hline C10 & Coverage of spatial plans & 0.02 & MAX \\
\hline C11 & Zone area & 0.02 & MAX \\
\hline C12 & Construction level degree/density & 0.02 & MAX \\
\hline C13 & Increase in construction level & 0.01 & MAX \\
\hline C14 & Traffic infrastructure coverage & 0.01 & MAX \\
\hline C15 & Available parking space capacity & 0.03 & MAX \\
\hline C16 & Water supply system coverage & 0.03 & MAX \\
\hline C17 & Sewer system coverage & 0.03 & MAX \\
\hline C18 & Power grid coverage & 0.03 & MAX \\
\hline C19 & Newly build facilities frequency & 0.08 & MAX \\
\hline C20 & Sold facilities frequency & 0.06 & MAX \\
\hline C21 & Utility charges and contributions & 0.09 & MAX \\
\hline C22 & Zone value & 0.09 & MAX \\
\hline
\end{tabular}

Table 1: Hierarchy levels and codes for the goals, objectives and criteria with assigned weights 
The experts were grouped into three expert groups: city government (group consisted of city mayor, his staff, and other city representatives), real estate agents and market experts (group consisted of experts from several respectable real estate agencies), and technical-economic experts (group consisted of civil engineering, urban development, and economic experts from the University of Split). Each group gave their preference to criteria according to the procedure shown in Figure 2. Table 1 gives their compromise view of criteria weights presented as an average weight for each criterion by three expert groups.

Based on previously described input parameters, a mathematical model was formed for ranking the zones in an urban area. The task was undertaken by means of the PROMETHEE II method and using the "Visual PROMETHEE" [9]. This software is based on the concept of systematic support for decisionmaking, providing a wide range of support for decision-making processes, where data are entered interactively, and most of the information and of obtained solutions can be visualized [10].

In addition to entering basic parameters and criteria weights from the decision matrix (Table 2), this method also requires selecting the criterion type allowing possible incoherence in the data set and preference functions that are to be corrected. Values presented in the decision matrix (Table 2) are the final research results [10], accompanied by a detailed description. A complex preference relation should be formed to emphasize the fact that an outranking relation is based on an appreciation of a number of criteria and on the generalization of criteria.

Defining the preference indexes results in the said complex preference relation, shown by means of a preference graph. The essence of this step is that the decision-maker must give priority to one of the two alternatives, i.e. actions in each of the criteria, based on the difference between the criteria values of the compared alternatives $[10,12]$.

The Usual Preference Function Type has been chosen for criteria C10 and C20, because the decision-maker deems all alternatives as indifferent if the difference between their values does not exceed the indifference threshold. The case when the difference exceeds the indifference threshold is called a strict preference. For the remaining 20 criteria, the decision makers did not have a clear attitude about the possible area of indifference between possible alternatives. In other words, the differences in the solution values based on these criteria are very important. Therefore, the V-shape Preference Function Type was chosen for these criteria, which in this case provides a good description of their attitudes. 


\begin{tabular}{|c|c|c|c|c|c|c|c|c|c|c|c|c|c|c|c|c|c|c|c|c|c|c|}
\hline \multirow{3}{*}{ City zone } & \multicolumn{22}{|c|}{ Criteria } \\
\hline & \multicolumn{7}{|c|}{ Social } & \multicolumn{2}{|c|}{ Ecological } & \multicolumn{9}{|c|}{ Technical and technological } & \multicolumn{4}{|c|}{ Economic } \\
\hline & C1 & $\mathrm{C} 2$ & $\mathrm{C} 3$ & C4 & C5 & C6 & C7 & $\mathrm{Cs}$ & C9 & C10 & C11 & C12 & C13 & C14 & C15 & C16 & C17 & C18 & C19 & C20 & C21 & C22 \\
\hline Bačvice & 2.82 & 0.349 & 0.097 & 7 & 9 & 10 & 8 & 8 & 6 & 10 & 2 & 22.346 & 4 & 21.957 & 7 & 9 & 9 & 10 & 4 & -18.71 & 1 & 2 \\
\hline Blatine-Škrape & 28.89 & 1.556 & 0.207 & 7 & 9 & 10 & 9 & 10 & 10 & 7 & 1 & 32.428 & 2 & 18.271 & 5 & 8 & 9 & 7 & 1 & -4.28 & 0.95 & 15 \\
\hline Bol & 2.22 & 0.106 & 0.206 & 5 & 9 & 10 & 8 & 8 & 9 & 10 & 2 & 31.949 & 5 & 21.200 & 4 & 7 & 7 & 5 & 2 & -3.80 & 0.95 & 14 \\
\hline Brda & 3.68 & 0.206 & 0.133 & 4 & 2 & 8 & 3 & 7 & 8 & 10 & 3 & 24.065 & 7 & 43.185 & 7 & 4 & 7 & 3 & 5 & -2.34 & 0.8 & 24 \\
\hline Grad & 19.08 & 1.832 & 0.328 & 10 & 10 & 10 & 10 & 4 & 7 & 10 & 1 & 56.397 & 3 & 27,404 & 4 & 9 & 7 & 8 & 2 & -16.22 & 1 & 1 \\
\hline Gripe & 21.02 & \begin{tabular}{|l|}
0.100 \\
\end{tabular} & 0.226 & 8 & 9 & 10 & 10 & 9 & 10 & 7 & 1 & 33.819 & 4 & 17.767 & 6 & 8 & 8 & 10 & 2 & 0.91 & 0.95 & 3 \\
\hline Kman & 17.64 & 0.144 & 0.194 & 4 & 6 & 9 & 7 & 6 & 9 & 7 & 1 & 28.330 & 6 & 18.201 & 5 & 5 & 7 & 4 & 3 & -6.15 & 0.8 & 19 \\
\hline Kocunar & 25.35 & \begin{tabular}{|l|}
0.139 \\
\end{tabular} & 0.156 & 4 & 6 & 9 & 7 & 6 & 9 & 7 & 1 & 20.895 & 6 & 22.043 & 4 & 5 & 7 & 4 & 3 & -5.40 & 0.8 & 21 \\
\hline Lokve & 33.54 & 0.150 & 0.148 & 7 & 7 & 9 & 10 & 8 & 9 & 7 & 1 & 24.962 & 7 & 20.776 & 5 & 7 & 7 & 9 & 2 & -4.63 & 0.95 & 7 \\
\hline Lovret & 6.38 & 0.328 & 0.204 & 10 & 9 & 9 & 7 & 5 & 8 & 10 & 2 & 31.276 & 5 & 11.178 & 5 & 7 & 7 & 8 & 3 & -2.78 & 0.95 & 10 \\
\hline Lučac-Manuš & 18.76 & 0.343 & 0.251 & 8 & 9 & 10 & 8 & 8 & 9 & 10 & 1 & 36.701 & 3 & 16.101 & 4 & 8 & 9 & 9 & 1 & 0.74 & 1 & 5 \\
\hline Mejasi & 1.47 & \begin{tabular}{|l|}
0.175 \\
\end{tabular} & 0.063 & 2 & 1 & 7 & 2 & 9 & 10 & 7 & 3 & 10.032 & 10 & 19.720 & 9 & 3 & 8 & 4 & 9 & -25.13 & 0.57 & 23 \\
\hline Meje & 2.80 & 0.033 & 0.040 & 4 & 5 & 9 & 2 & 2 & 2 & 10 & 2 & 19.935 & 2 & 8.040 & 7 & 7 & 9 & 7 & 3 & 12.46 & 1 & 4 \\
\hline Merojak & 18.21 & \begin{tabular}{|l|}
0.146 \\
\end{tabular} & 0.131 & 6 & 5 & 9 & 5 & 6 & 9 & 7 & 1 & 21.257 & 5 & 15.952 & 5 & 7 & 8 & 7 & 1 & 0.95 & 1 & 13 \\
\hline Neslanovac & 3.78 & \begin{tabular}{|l|}
0.239 \\
\end{tabular} & 0.137 & 2 & 2 & 7 & 2 & 9 & 10 & 7 & 2 & 17.679 & 7 & 20.073 & 6 & 4 & 6 & 3 & 9 & 16.69 & 0.57 & 22 \\
\hline Plokite & 27.46 & \begin{tabular}{|l|}
0.140 \\
\end{tabular} & 0.152 & 5 & 8 & 8 & 8 & 6 & 8 & 7 & 1 & 23.957 & 4 & 22.469 & 4 & 7 & 7 & 7 & 2 & -14.68 & 0.95 & 17 \\
\hline Pujanke & 23.96 & 0.101 & 0.125 & 4 & 6 & 9 & 6 & 8 & 9 & 7 & 1 & 17.430 & 4 & 16.875 & 5 & 6 & 7 & 6 & 3 & -2.34 & 0.8 & 20 \\
\hline Ravne njive & 14.84 & \begin{tabular}{|l|}
0.352 \\
\end{tabular} & 0.135 & 3 & 5 & 9 & 6 & 7 & 9 & 7 & 1 & 20.240 & 5 & 27.642 & 4 & 5 & 7 & 4 & 4 & -34.21 & 0.8 & 25 \\
\hline Sirobuja & 2.29 & 0.010 & 0.023 & 1 & 1 & 7 & 1 & 7 & 4 & 7 & 2 & 3.823 & 7 & 21,387 & 9 & 2 & 2 & 3 & 7 & 4.21 & 0.57 & 27 \\
\hline Split 3 & 1.85 & 0.181 & 0.114 & 8 & 8 & 9 & 9 & 9 & 9 & 7 & 2 & 29.128 & 3 & 16.895 & 5 & 8 & 9 & 7 & 1 & \begin{tabular}{|l|}
-11.81 \\
\end{tabular} & 0.95 & 11 \\
\hline Sućidar & 2.28 & 0.160 & 0.192 & 8 & 7 & 9 & 5 & 9 & 9 & 10 & 1 & 25.991 & 5 & 12.951 & 7 & 7 & 7 & 6 & 3 & 7.20 & 0.95 & 18 \\
\hline Šine & 3.27 & \begin{tabular}{|l|}
0.165 \\
\end{tabular} & 0.117 & 1 & 2 & 8 & 1 & 8 & 9 & 10 & 1 & \begin{tabular}{|l|}
16.030 \\
\end{tabular} & 7 & 16.970 & 7 & 2 & 1 & 3 & 7 & 12.29 & 0.57 & 26 \\
\hline Špinut & 5.74 & \begin{tabular}{|l|}
0.145 \\
\end{tabular} & \begin{tabular}{|l|}
0.047 \\
\end{tabular} & 6 & 7 & 9 & 4 & 3 & 3 & 10 & 3 & 32.359 & 7 & 06.769 & 4 & 7 & 8 & 6 & 5 & -5.92 & 0.95 & 9 \\
\hline Trstenik & 10.45 & \begin{tabular}{|l|}
0.198 \\
\end{tabular} & \begin{tabular}{|l|}
0.108 \\
\end{tabular} & 6 & 9 & 9 & 8 & 5 & 7 & 10 & 2 & 23,477 & 8 & 13.721 & 5 & 8 & 7 & 7 & 3 & -9.77 & 1 & 8 \\
\hline Varos & 2.75 & \begin{tabular}{|l|}
0.071 \\
\end{tabular} & \begin{tabular}{|l|}
0.046 \\
\end{tabular} & 6 & 9 & 10 & 2 & 7 & 3 & 10 & 3 & 41.022 & 3 & 01.628 & 3 & 9 & 7 & 8 & 5 & 23.88 & 1 & 12 \\
\hline Visoka & 9.89 & \begin{tabular}{|l|}
0.187 \\
\end{tabular} & \begin{tabular}{|l|}
0.170 \\
\end{tabular} & 5 & 5 & 9 & 6 & 9 & 9 & 10 & 1 & 22.466 & 9 & 19.173 & 5 & 7 & 7 & 7 & 3 & -3.15 & 0.8 & 16 \\
\hline Žnjan & 2.01 & \begin{tabular}{|l|}
0.096 \\
\end{tabular} & \begin{tabular}{|l|}
0.068 \\
\end{tabular} & 2 & 5 & 9 & 5 & 4 & 2 & 10 & 3 & 10.380 & 10 & 13.428 & 10 & 6 & 75 & 76 & 10 & 23.45 & 1 & 6 \\
\hline
\end{tabular}

Table 2: Decision matrix

Numerical processing was performed on all input data, with the results shown in Table 3. Using the PROMETHEE II method, total "Phi" values of flows were obtained. In other words, the method provided the sum of all input and output flows, with particular pairs of actions being dominant. The result is the rank-list of all observed zones in the City of Split sorted from best (Žnjan) to worst (Mejaši).

Combining the results from PROMETHEE II (Table 3) with spatial tools, such as GIS tools, gave a valuable insight into compared zones based on a defined set of criteria (see Figure 4). This visual presentation of ranking results enables decision-makers to gain rapid insight into the quality of compared zones, and provides an answer to the question, "Where to invest?" Importantly, the presented model does not give an answer to the question of "What to invest in?" This is a frequently asked question when the quality of compared zones is spatially dispersed. Additional qualitative and quantitative analysis of each zone can provide answers to further questions. 


\begin{tabular}{|c|c|c|c|c|c|}
\hline Rank & City zone & City zone code & Phi & Phi+ & Phi- \\
\hline 1. & Žnjan & Z 27 & 0.3220 & 0.4304 & 0.1085 \\
\hline 2. & Grad & $\mathrm{Z} 5$ & 0.2958 & 0.3998 & 0.1041 \\
\hline 3. & Meje & Z 13 & 0.2592 & 0.3823 & 0.1231 \\
\hline 4. & Varoš & $\mathrm{Z} 25$ & 0.2288 & 0.3517 & 0.1229 \\
\hline 5. & Bačvice & Z 1 & 0.1920 & 0.3121 & 0.1201 \\
\hline 6. & Špinut & Z 23 & 0.1827 & 0.3181 & 0.1354 \\
\hline 7. & Lučac-Manuš & Z 11 & 0.1825 & 0.3045 & 0.1220 \\
\hline 8. & Gripe & $\mathrm{Z} 6$ & 0.1527 & 0.2967 & 0.1440 \\
\hline 9. & Trstenik & Z 24 & 0.1334 & 0.2641 & 0.1307 \\
\hline 10. & Lovret & Z 10 & 0.1212 & 0.2512 & 0.1300 \\
\hline 11. & Lokve & Z 9 & 0.0561 & 0.2184 & 0.1623 \\
\hline 12. & Mertojak & Z 14 & 0.0293 & 0.2049 & 0.1756 \\
\hline 13. & Blatine-Škrape & $\mathrm{Z} 2$ & 0.0183 & 0.2315 & 0.2132 \\
\hline 14. & Bol & Z 3 & 0.0068 & 0.1877 & 0.1809 \\
\hline 15. & Sućidar & Z 21 & -0.0066 & 0.1911 & 0.1977 \\
\hline 16. & Split 3 & $\mathrm{Z} 20$ & -0.0226 & 0.1879 & 0.2105 \\
\hline 17. & Plokite & Z 16 & -0.0484 & 0.1729 & 0.2212 \\
\hline 18. & Visoka & Z 26 & -0.1108 & 0.1351 & 0.2460 \\
\hline 19. & Kman & Z 7 & -0.1381 & 0.1330 & 0.2711 \\
\hline 20. & Kocunar & Z 8 & -0.1534 & 0.1230 & 0.2764 \\
\hline 21. & Pujanke & Z 17 & -0.1643 & 0.1147 & 0.2790 \\
\hline 22. & Brda & $\mathrm{Z} 4$ & -0.1710 & 0.1377 & 0.3087 \\
\hline 23. & Neslanovac & Z 15 & -0.2369 & 0.1426 & 0.3795 \\
\hline 24. & Sirobuja & Z 29 & -0.2490 & 0.1672 & 0.4162 \\
\hline 25. & Ravne njive & Z 18 & -0.2558 & 0.0809 & 0.3368 \\
\hline 26. & Šine & $\mathrm{Z} 22$ & -0.2805 & 0.1166 & 0.3970 \\
\hline 27. & Mejaši & Z 12 & -0.3432 & 0.1049 & 0.4482 \\
\hline
\end{tabular}

Table 3: Rank-list of all zones in the city of Split - result of PROMETHEE II Complete Ranking

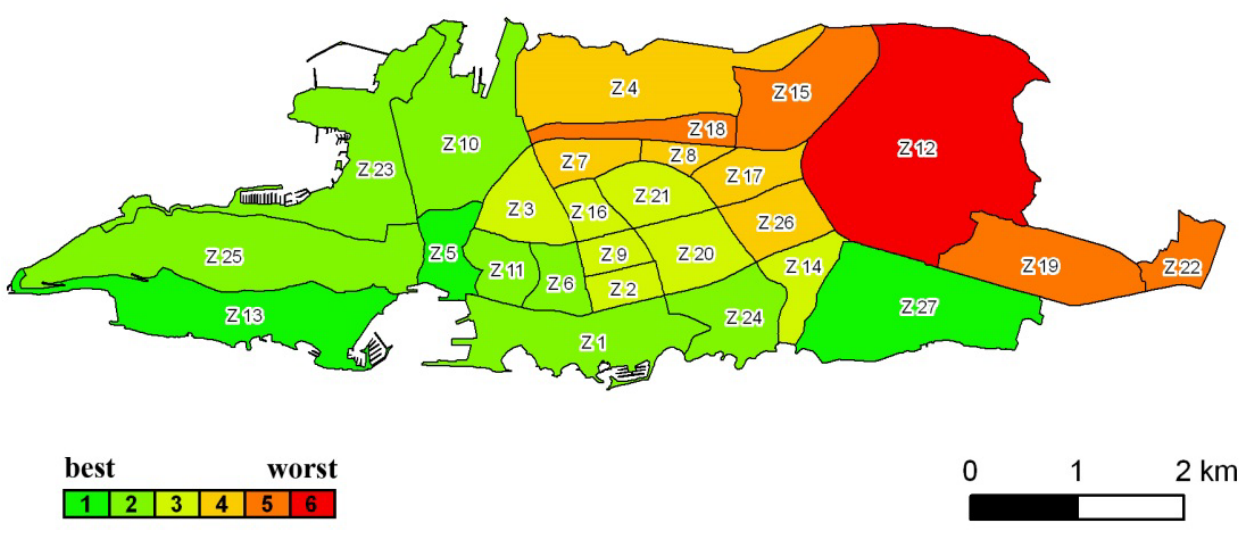

Figure 4: Spatial presentation of RZM for the City of Split 


\section{Conclusion}

This paper has presented a model for evaluating and ranking zones in an urban area based on multiple-criteria analysis. The model was fed with spatial information and data based on the views of interest groups (city government, real estate agents and market experts, technical-economic experts). The hierarchical goal structure for mutual comparison of zones was also introduced. It has been shown that implementation of the multiple-criteria analysis can contribute to better quality and more consistent decision-making for the spatial management of urban areas.

The value of this model lies in the consistency of the decision-making process. It gives the decision-maker a sense of assurance, knowing that if the procedure proposed by the presented model has been followed, it will lead to a rational decision, carefully and systematically thought out. The advantage of this decision-making approach lies in the fact that even if it a change in the structure of decision-makers occurs, the actual decision-making procedure remains consistent.

\section{References}

[1] Brans, J.P., Mareschal, B. and Vincke, Ph. (1984). PROMETHEE: A new family of outranking methods in MCDM. Operational Research '84 - Proceedings of the 10th IFORS International Conference on Operational Research, 1984, Elsevier Science Publishers, Washington.

[2] Brans, J.P. and Mareschal, B. (2005). PROMETHEE methods. In: Figueira, J., Greco, S. and Ehrgott, M. (Eds.). Multiple Criteria Decision Analysis: State of the Art Surveys (pp. 163-196). New York: Springer.

[3] Chakrabarty, B.K. (2001). Urban management - concepts, principles, techniques and education. Cities, 18(5), 331-345.

[4] Hanak, T., Marović, I. and Pavlović, S. (2014). Preliminary identification of residential environment assessment indicators for sustainable modelling of urban areas. International Journal for Engineering Modelling, 27(1-2), 61-68.

[5] Jajac, N. (2010). Decision support system for development and maintenance of urban road infrastructure. $\mathrm{PhD}$ Thesis, Split: University of Split, Faculty of Economics. (in Croatian)

[6] Jajac, N., Bilić, I. and Alduk, A. (2013). Decision support concept to management of construction projects - problem of construction site selection. Croatian Operational Research Review, 4, 235-246.

[7] Jajac, N., Bilić, I. and Mladineo, M. (2012). Application of multicriteria methods to planning of investment projects in the field of civil engineering. Croatian Operational Research Review, 3, 113-124. 
[8] Jajac, N., Knezić, S. and Marović, I. (2009). Decision support system to urban infrastructure maintenance management. Organization, Technology \& Management in Construction, 1(2), 72-79.

[9] Mareschal, B. (2012). Visual PROMETHEE, ver.0.9.5. http://prometheegaia.net/software.html [Accessed on 31 March 2012].

[10] Marović, I. (2013). Decision support system in real estate value management. PhD Thesis, Zagreb: University of Zagreb, Faculty of Civil Engineering. (in Croatian)

[11] Marović, I. and Hanak, T. (2013). Identification of indicator influence in residential environment assessment. Proceedings of the Faculty of Civil Engineering in Rijeka, $16,113-127$.

[12] Marović, I., Car-Pušić, D. and Hrvatin Z. (2014). Establishing a model to evaluate public administration projects. e-GFOS, 8, 56-66. doi:10.13167/2014.8.7.

[13] Medvedec, D., Bošković, D. and Marović, I. (2012). Public infrastructure project management in local government units financed by EU founds. Proceedings of the Faculty of Civil Engineering in Rijeka, 15, 203-222.

[14] Shen, L-Y., Ochoa, J.J., Shah, M.N. and Zhang, X. (2011). The application of urban sustainability indicators - a comparison between various practices. Habitat International, 35, 17-29. doi:10.1016/j.habitatint.2010.03.006.

[15] Ugwu, O.O., Kumaraswamy, M.M., Wong, A. and Ng, S.T. (2006). Sustainability appraisal in infrastructure projects (SUSAIP) Part 1. Development of Indicators and Computational Methods. Automation in Construction, 15, 239-251. doi:10.1016/j.autcon.2005.05.006.

[16] UN Habitat. (2013). For a better urban future, urban development and management. http://www. unhabitat.org [Accessed on 13 October 2014].

[17] Vincke, P. (1992). Multicriteria Decision-Aid. Bruxelles: Wiley\&Sons.

[18] Zhang, K., Wen, Z., Du, W. and Song, G. (2008). A multiple-indicators approach to monitoring urban sustainable development. Ecology, Planning, and Management of Urban Forests, 35-52. doi:10.1007/978-0-387-71425-7_4. 